\title{
LOTE ECONÔMICO DE PRODUÇÃO: CONCEITO E PRÁTICA WOLFGANG SCHOEPS
}

A determinação prévia das quantidades a serem fabricadas torna a produção mais econômica, efficlente e harmoniosa.

Observando os procedimentos e rotinas de planejamento de numerosas indústrias de nosso parque industrial, chega-se à conclusão de que é pràticamente inexistente o processo de análise e posterior determinação das quantidades mais econômicas a serem produzidas para cada produto, artigo, componente ou item. A análise econômica para determinação das quantidades de produção tem por finalidade obter o menor custo final para cada item. Devido à necessidade prática de produzir quantidades freqüentemente maiores do que aquelas exigidas de imediato pelas ordens de fabricação em andarnento, a fim de reduzir os custos de preparação do equipamento, como, por exemplo, a troca de ferramentas, os custos de movimentação de materiais e as despesas de natureza administrativa, a emprêsa aumenta forçosamente o seu estoque.

Ora, em nossa atual conjuntura financeira, com as restrições existentes à obtenção de crédito e o consequiente custo elevado do capital emprestado, a decisão de manter estoques elevados, se de um lado pode ser conveniente à produção, certamente entrará em choque com os interêsses

WolfGang Schoeps - Professor-Adjunto do Departamento de Administração da Produção e Coordenador do "Curso Intensivo para Administradores" da Escola de Administração de Emprêsas de São Paulo. 
e as possibilidades do setor financeiro da emprêsa. Havendo, assim, duas tendências opostas, torna-se necessária uma análise precisa para determinar a quantidade correta a ser produzida, isto é, aquela quantidade que, do ponto de vista do custo final do produto, corresponde às condições mais favoráveis.

Como o cálculo da quantidade econômica de produção pressupõe uma previsão das necessidades do mercado ou das quantidades a serem requisitadas durante determinado período, o setor de contrôle de materiais, dentro do departamento de planejamento e frogramação de uma indústria, poderá desincumbir-se da tarefa de analisar e fixar estas quantidades. Nas emprêsas observadas, que possuem a função de planejamento da produção, existem normalmente os elementos que permitem fazer êsses cálculos. Mesmo que se utilizem dados aproximados, é lícito afirmar que as indicações serão bastante significativas no sentido de racionalizar êste aspecto quantitativo da produção (1).

A ORDEM DE FABRICAÇÃO E O LOTE ECONÔMICO

Sempre que uma ordem de fabricação é emitida pelos responsáveis pela produção, surge, na indústria, o problema de fixar de modo preciso a quantidade a ser fabricada. Ademais, dependendo do destino e da aplicação dos itens constantes das ordens de fabricação (O.F.), apresentam-se diversas alternativas. Assim, bàsicamente, os seguintes casos devem ser considerados na emissão de ordens de fabricação:

1. O. F. de itens sob encomenda especial. - Tratando-se de peças ou artigos a serem produzidos de acôrdo com as especificações do cliente, e não sendo padronizadas, sua quantidade será aquela da encomenda, acrescida de um número correspondente aos eventuais refugos durante o processo de fabricação.

1) J. F. Magee, Production Planning and Inventory Control, McGraw-Hill Book Co. Inc., New York, 1958, pág. 46. 
2. O. F. de itens sob encomenda padronizada. - Neste caso, é possível que o número de peças que corresponde ao pedido possa ser obtido parcial ou integralmente do estoque, o que, conseqüentemente, diminuirá a quantidade a ser lançada na O. F. Por outro lado, será examinada a conveniência de produzir também uma quantidade maior do que aquela do pedido para obter ou aumentar a estocagem do produto.

3. O.F. de itens seriados. - Quando existe a política de manter um produto em estoque para atender a um número elevado de clientes, êsse será, quase sempre, um produto padronizado e fabricado em série. Cada O. F. deverá, então, determinar o número de unidades em cada série a ser fabricada, do que resultará a frequiência dos ciclos de produção.

É mais comum encontrarem-se em nossas fábricas os níveis de estcque mínimo computados para os diversos materiais, mas êsses elementos não são significativos para a determinação da quantidade de cada suprimento, pois o lote econômico de produção (Q.E.P.) é adicionado ao estoque mínimo e esta soma será equivalente ao estoque máximo, pois,

$$
\text { Estcque mínimo + Q.E.P. = Estoque máximo. }
$$

Se, de um lado, é mais econômico produzir quantidades maiores, minimizando os custos da mudança do equipamento e obtendo rendimento industrial mais alto na fabricação de lotes maiores, como já dissemos, por serem estas quantidades em excesso à demanda imediata, haverá a formação de estoques. Êstes, na atual conjuntura, são gravados por encargos financeiros da ordem de 30 a $60 \%$ a. a., variáveis conforme as circunstâncias e constituídos da taxa de juros correspondente ao capital empatado, do custo do espaço referente ao armazenamento, das taxas de 
seguros e do custo decorrente de eventual deterioração e obsolescência do material. Na situação inflacionária, as taxas de juros são mais elevadas, contrabalançando assim a elevação dos preços de material estocado. Êste aspecto da análise é, aliás, bastante semelhante ao cálculo dos custos de armazenamento com materiais adquiridos de terceiros, sendo válidas aqui as mesmas considerações feitas para o cálculo do lote econômico de compra (2).

Sendo de rotina efetuar a indústria a reposição de materiais, a assim chamada valorização do estoque durante períodos inflacionários é bastante fictícia e, na realidade, apenas resulta na apresentação de lucros contábeis. Se êsse lucro contábil fôr insuficiente para repor o mesmo material no estoque, será, efetivamente, um prejuízo, apesar de aparecer como lucro e, everitualmente, estar sujeito a tributação fisca!.

A quantidade econômica de produção é influenciada pela variação da taxa de juros e, consequientemente, pela inflação, mas é calculada em função das quantidades de venda ou de uso previstos, fazendo-se abstração da especulação de estoques. Aliás, nossas emprêsas, via de regra, preferem a rotação rápida do seu estoque ao armazenamento para valorização, pois o lucro unitário de cada operação multiplicado pelo coeficiente de rotação do estoque oferece sempre um resultado final mais favorável do que a manutenção e valorização do estoque durante períodos mais longos. Assim, será preferível, por exemplo, vender doze vêzes ao ano com a margem normal, do que aguardar e vender apenas duas vêzes. Isto, aliás, seria extremamente difícil, considerando limitações práticas como a necessidade de manter constante a produção da fábrica, o conseqüente investimento em estoques e os custos mais elevados de reposição, em relação aos preços de venda.

2) Vide Wolfgang Schoeps, "A Determinação da Quantidade Econômica nas Compras Industriais", Revista Idort, vol. XXVIII, nºs. 327-328, págs. 19 a 21 e Claude Machline, "Inflação e Lote Econômico de Compra", Revista de Administração de Emprếsas, vol. 1, n. 1, págs. 17 a 33. 
CÁlCULO DO LOTE ECONÔMICO DE PRODUÇÃO

O processo de cálculo do lote econômico de produção visa a conhecer o custo mínimo total para determinado item durante certo periodo, normaimente um ano. Há duas hipóteses básicas a considerar:

$1 .^{a}$ ) - quando o material produzido chega ao estoque em um só lote e sua retirada é uma função contínua;

2. ${ }^{a}$ ) - quando o material produzido chega ao estoque em parcelas e durante certo período, no decorrer do qual ocorre também certa retirada dêste mesmo material.

$\mathrm{Na} 1 .^{\text {a }}$ hipótese. os níveis de estoque apresentam o perfil do Gráfico 1.

GRÁFICO 1: NÍVEIS DE ESTOQUE - 1. ${ }^{a}$ HIPÓTESE

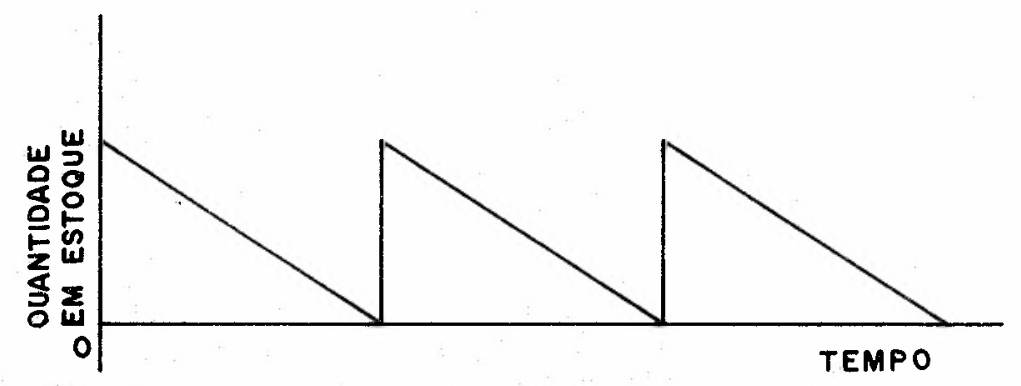

Sendo:

$Q=$ Quantidade ou lote econômico de produção em unidades

$\mathrm{K}=$ Custo total anual em cruzeiros

$\mathbf{R}=$ Necessidades anuais usadas ou vendidas em unidades

$\mathrm{C}=$ Custo de fabricação de cada unidade 
$\mathbf{P}=$ Custo de preparação e ajuste das máquinas para cada O.F. "set-up cost" ou custo de mudança, inclusive horas passivas

$I=$ Taxa de encargos financeiros que gravam o estoque em $\%$ a. a.,

o custo total anual será a soma dos custos de fabricação (RC), dos custos de preparação $\left(\frac{R}{Q} P\right)$ e dos encargos financeiros sôbre o estoque médio $\left(\begin{array}{lll}\frac{Q}{2} & C & I\end{array}\right)$. Portanto,

$$
\mathrm{K}=\mathrm{RC}+\frac{\mathrm{R}}{\mathrm{Q}} \mathrm{P}+\frac{\mathrm{Q}}{2} \mathrm{CI}
$$

Por definição, a quantidade ou lote econômico de produção corresponde às condições em que o custo total anual fôr mínimo. (Gráfico 2).

Êste custo total anual será mínimo quando

$$
\frac{\mathrm{dK}}{\mathrm{dQ}}=\mathrm{O}
$$

Portanto,

$$
\frac{\mathrm{dK}}{\mathrm{dQ}}=-\frac{\mathrm{RP}}{\mathrm{Q}^{2}}+\frac{\mathrm{CI}}{2}=\mathrm{O}
$$

e,

$$
\mathrm{Q}=\sqrt{\frac{2 \mathrm{RP}}{\mathrm{CI}}}
$$

$\mathrm{Na} 2 .^{\mathrm{a}}$ hipótese, admitiu-se que o material não chega ao estoque em um só lote, mas continuamente, em parcelas, durante certo período, no decorrer do qual há saída de forma contínua. $O$ comportamento dos níveis de estoque apresentará, portanto, o perfil do Gráfico 3 . 
GRÁFICO 2: QUANTIDADE ECONÔMICA DE PRODUÇÃO

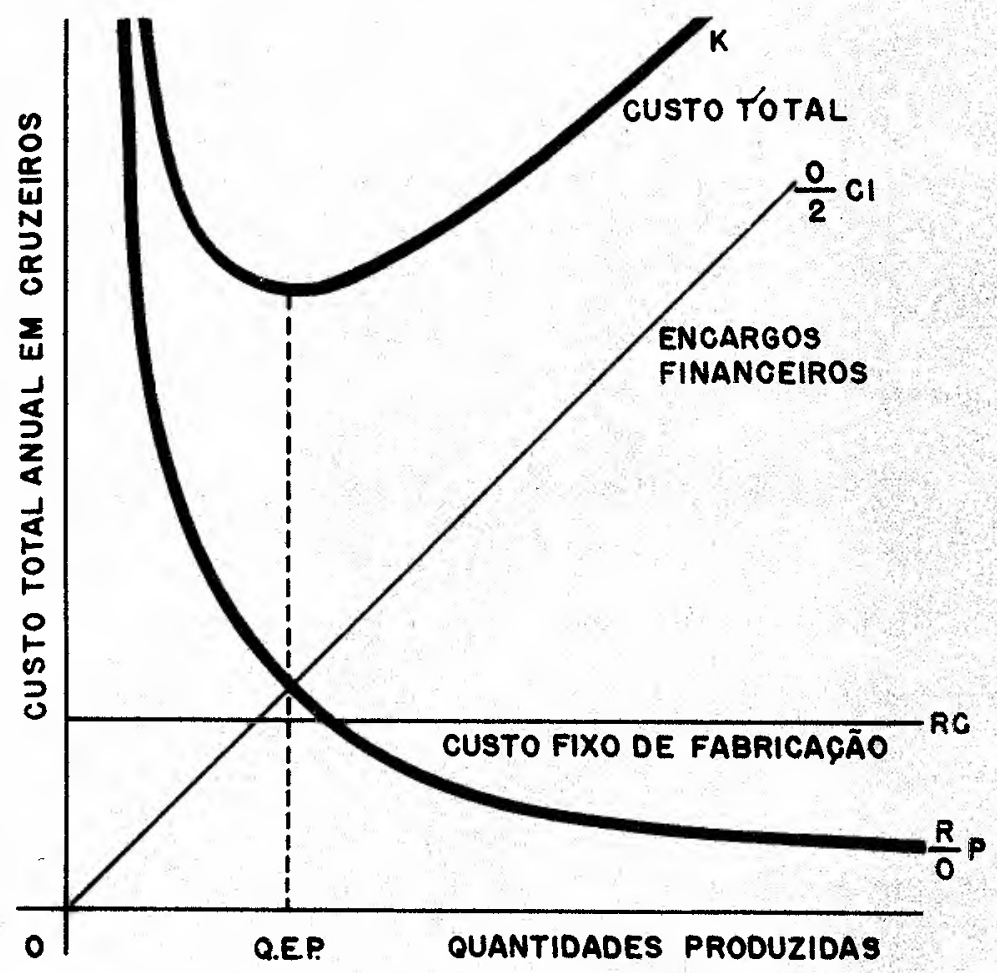

GRÁFICO 3: NÍVEIS DE ESTOQUE - 2. HIPÓTESE $Q\left(1-\frac{R}{s}\right)$

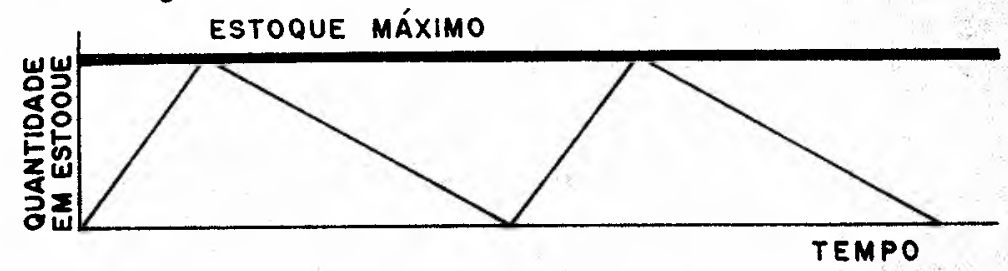


Damos, a seguir, um exemplo de determinação de estoque máximo e de estoque médio.

Se, para certo artigo, a Q.E.P. é de 40.000 peças usinadas e se estas apenas podem ser feitas em uma máquina que produz 2.000 peças por dia, 20 dias, aproximadamente, serão necessários para liquidar a crdem de fabricação. Sendo o consumo diário igual a $\mathbf{5 0 0}$ peças e não existindo estoque inicial, o estoque ao fim de 20 dias será 40.000 $10.000=30.000$ peças.

Fazendo

$\mathrm{Q}=$ Q.E.P. ou número totál de peças pedidas

$\mathbf{R}=$ Consumo em unidades por tempo

$\mathrm{S}=$ Produção em unidades por tempo,

sendo $\mathrm{S}>\mathrm{R}$,

teremos

Estoque Máximo $=\mathrm{Q}-\left(\frac{\mathrm{Q}}{\mathrm{S}} \mathrm{R}\right)=\mathrm{Q}\left(1-\frac{\mathrm{R}}{\mathrm{S}}\right)$ e

Estoque Médio $=\frac{\mathrm{Q}}{2}\left(1-\frac{\mathrm{R}}{\mathrm{S}}\right)$

Nesta hipótese, o custo total anual será dado pela expressão

$$
\mathrm{K}=\mathrm{CR}+\frac{\mathrm{RP}}{\mathrm{Q}}+\mathrm{CI} \frac{\mathrm{Q}}{2}\left(1-\frac{\mathrm{R}}{\mathrm{S}}\right)
$$

que, mais uma vez, representa a soma dos custos de fabricação, de preparação e dos encargos financeiros. 
Devendo K ser mínimo,

e

$$
\frac{\mathrm{dK}}{\mathrm{dQ}}=\mathrm{O}
$$

$$
\frac{\mathrm{dK}}{\mathrm{dQ}}=-\frac{\mathrm{RP}}{\mathrm{Q}^{2}}+\frac{\mathrm{CI}}{2}\left(1-\frac{\mathrm{R}}{\mathrm{S}}\right)=\mathrm{O}
$$

Portanto:

$$
Q=\sqrt{\frac{2 R P}{C I\left(1-\frac{R}{S}\right)}}
$$

FREQƯÊNCIA DAS ORDENS DE FABRICAÇÃO

Conhecendo o total das necessidades anuais de material, será de interêsse para o planejamento conhecer o número de ordens de fabricação que devem ser emitidas cada ano. Desta forma, poderá ser estabelecido um sistema repetitivo e automático de emissão de ordens de fabricação pelo planejamento, passando a constituir simples rotina, a ser executada pelos funcionários subalternos da seção. Esta rotina é semelhante à determinação dos "pontos de pedidos" para as compras industriais.

A frequiência das ordens de fabricação por ano ( $n$ ) pode ser obtida da relação

$$
\mathrm{n}=\frac{\mathrm{R}}{\mathrm{Q}}=\frac{\mathrm{R}}{\sqrt{\frac{2 \mathrm{RP}}{\mathrm{CI}\left(1-\frac{\mathrm{R}}{\mathrm{S}}\right)}}}
$$


Portanto,

$$
\mathrm{n}=\sqrt{\frac{\mathrm{RCI}\left(1-\frac{\mathrm{R}}{\mathrm{S}}\right)}{2 \mathrm{P}}}
$$

CICLO DE PRODUÇÃO E PRODUTOS MÚLTIPLOS

Quando se trata de produzir com o mesmo equipamento diversos produtos em sequiência, a duração total do ciclo de produção depende dos mesmos fatôres econômicos que determinaram o lote econômico de produção. A ordem de seqüência será, usualmente, determinada em função do menor custo de mudança de um tipo de produção para outro. Assim, por exemplo, na fabricação de papel há conveniências econômicas e técnicas no iniciar um ciclo de produção com os tipos mais leves, terminando-se com os mais pesados.

Tratando-se, portanto, de diversos produtos de 1.......i, todos fazendo parte de cada ciclo de produção, a fórmula para chegar ao número total de ciclos de produção por ano $(n)$ será:

$$
n=\sqrt{\frac{\Sigma_{1}^{1} R_{i} C_{i} I_{1}\left(1-R_{i} / S_{i}\right)}{2 \Sigma_{1}^{1} P_{i}}}
$$

A quantidade econômica de produção para um produto individual $i$ dentro do ciclo total será:

$$
\mathbf{Q}_{1}=\frac{\mathbf{R}_{\mathbf{I}}}{\mathbf{n}}
$$

e substituindo $n$ na fórmula acima, teremos: 


$$
Q_{i}=\sqrt{\frac{2 R_{i} \Sigma_{1}^{1} P_{i}}{\Sigma_{1}^{i} C_{i} I_{i}\left(1-R_{i} / S_{i}\right)}}
$$

A determinação do ciclo econômico de produção com diversos produtos é necessária, por exemplo, na indústria química ou petroquímica, em que se processam diversos tipos de produtos na mesma unidade para serem, em seguida, estocados. Também as mudanças numa linha de fabricação de vasilhames ou, ainda, o acondicionamento do mesmo produto em diversas embalagens poderá sofrer a determinação econômica da quantidade Qi a ser produzida durante cada ciclo ( 3 ).

\section{CASOS PRÁTICOS OBSERVADOS}

Um problema interessante ocorre nas relações entre compradores e fornecedores quando peças ou conjuntos fabricados pelos segundos são adquiridos para os processos de montagem ou para incorporação ao produto final dos compradores. Êste é, por exemplo, o caso da relação entre fabricantes de auto-peças e as fábricas montadoras de veículos. Êstes últimos, na posição de compradores, estão interessados em manter seus estoques no nível mínimo compatível com a continuidade da produção, desejando receber lotes pequenos e freqüentes. Esta posição é conflitiva com o interêsse do fornecedor, pois para êle será mais econômico produzir lotes maiores, tão próximos do lote econômico de produção quanto fôr possível.

Assim, em determinados casos, lcte econômico de produção e lote econômico de compra representam interêsses antagônicos, devido ao simples fato de que cada uma das partes, na operação, deseja minimizar seus custos. Sob certas condições, o fornecedor preferirá a produção de um número maior de peças em cada lote do que o garantido

3) Para um exemplo numérico vide Anexo 1. 
pelo programa de recebimentos do comprador, arcando, portanto, com os encargos financeiros da estocagem. Esta prática será perfeitamente justificável, aliás, se êsses encargos forem menores do que o custo de preparação para a fabricação de um nôvo lote. Do contrário, será recomendável que o fornecedor faça seus orçamentos de custo sempre de acôrdo com as quantidades de entrega especificadas para cada período.

Neste sentido, foi observado numa fábrica de auto-peças em São Paulo que determinada peça estampada de chapa de ferro, destinada à montagem de automóveis e que passa por 13 operações, acarreta um custo de preparação $P=$ Cr $\$ 12.000,00$. O custo unitário de fabricação desta peça é de Cr $\$ 800,00$ e o programa de entregas estipula uma quota mensal de 2.000 peças, que podem ser produzidas em 3 dias. Considerando para a emprêsa em questão a taxa de encargos financeiros I igual a 3\% ao mês, a quantidade econômica de produção $Q$ será: (4)

$$
\text { Q.E.P. }=\sqrt{\frac{2 \times 2.000 \times 12.000}{800 \times 0,03}}=1.410 \text { unidades }
$$

Considerando a necessidade anual do comprador igual a 24.000 unidades, o número de ciclos anuais de produção (n) será $\frac{R}{Q}$, ou seja, igual a 16. Portanto, para efeito prático, cada três semanas deverá ser fabricado um lote de aproximadamente 1.500 peças.

Todavia, tanto por parte do fornecedor ccmo por parte da montadora, é bastante comum existir uma flutuação do nível mensal da atividade da fábrica, resultando em capacidade de produção disponível ou, então, em atividade além da previsão. Para o fornecedor do exemplo acima citado, durante um certo mês houve pouco trabalho

4) Aplicando valôres mensais de $R$ e I na fórmula (I). 
programado e, assim, resolveu-se estudar a possibilidade de produzir 2 lotes durante aquêle mês, isto é, fabricar um lote de 3.000 peças, deixando 1.500 em estoque durante mais 3 semanas. Adicionou-se, portanto, uma despesa com estocagem de $\mathrm{Cr} \$ 27.000,00 \mathrm{da}$ qual se subtraíram $\mathrm{Cr} \$ 12.000,00$ decorrentes da economia de preparação. Ficaria, assim, um saldo de $\mathrm{Cr} \$ 15.000,00$ a onerar o custo final da produção, mas, na realidade, temos que considerar a mão-de-obra direta que foi absorvida devido à decisão de produzir dois lotes de uma só vez. Não fôsse essa a providência tomada, a mão-de-obra para as 1.500 peças adicionais teria ficado sem aproveitamento, gravando o custn de outras ordens de fabricação. A título de informa.ção, a mão-de-obra direta para a produção de cada Q.E.P. importava em $\mathrm{Cr} \$ 30.000,00$ e a desvantagem aparente de Cr $\$ 15.000,00$ transformou-se, desta maneira, numa economia da mesma importância.

Outra ocorrência observada foi a redução por parte do comprador da quota para $\mathbf{5 0 0}$ unidades durante determinado mês. Podemos dizer, a priori, que dois terços do custo de preparação não puderam ser absorvidos, havendo um aumento de $\mathrm{Cr} \$ \mathbf{8 . 0 0 0 , 0 0}$ no custo de produção do lote, ou seja, de $\operatorname{Cr} \$ 16,00$ por peça. Êste aumento do custo unitário seria, porém, algumas vêzes maior, se considerássemos a mão-de-obra e as despesas gerais de fabricação não absorvidas, sem falar de lucro cessante. Aliás, sòmente essas despesas gerais não absorvidas importariam em $\mathrm{Cr} \$$ 23.000,00. Na praxe comercial não é comum, num caso semelhante a êste, aumentar o preço do produto durante apenas um período, mas, a persistir a redução quantitativa, seria necessário recalcular o custc em função das quantidades reduzidas.

$\mathrm{Na}$ indústria têxtil, a determinação do lote econômico de compra tem múltiplas aplicações, principalmente na fixação de diretrizes quanto à conveniência de preparar e produzir maior metragem de certos artigos na tecelagem. Determinada tecelagem de lã em São Paulo eleva a perda de sua produção de 2 para 10\% quando certos padrões 
de tecido de lã são produzidos em lotes de 200 metros em vez de 1.000 metros. Esta perda de produção é particularmente onerosa quando se consideram as elevadas despesas gerais de fabricação e o lucro cessante em instalações de tal porte. Por outro lado, o elevado custo unitário da mercadoria e o maior risco de mudança da moda exigem especial atenção para a análise dêste problema e a consequiente formulação de diretrizes econômicas neste setor.

\section{CONCLUSÓES}

Sendo divergentes do ponto de vista econômico os interêsses da manutenção de estoques e da redução dos custos da produção, apenas uma análise minuciosa dos fatôres expostos fornecerá ao dirigente responsável pela gestão da emprêsa as indicações precisas de que necessita. Apesar de as fórmulas oferecidas para o cálculo do lote econômico de produção serem de aplicação simples e rápida, será mais importante a perfeita compreensão de todos os elementos de custo envolvidos direta ou indiretamente na solução do problema.

$\mathrm{Na}$ presente conjuntura inflacionária, alguns elementos de custo sofrem variações contínuas, como a taxa de encargos financeiros do estoque, que, para cada tipo de produto e mesmo para cada emprêsa, terá valôres próprios. Além disso, mesmo determinada essa taxa, será preciso ter em mente o limite disponível em valor absoluto para inversões no estoque, quer de produtos acabados, quer de produtos semi-acabados. Em alguns casos, os resultados dos cálculos serão adotados integralmente e, em outros, servirão de referência básica para equacionar o problema "produção - estoque". Para a maioria das emprêsas, a análise das quantidades a serem fabricadas motivará uma revisão da sua política de estoques e, possivelmente, contribuirá para uma rotação mais rápida de seus produtos, de acôrdo com a evolução dos custos de estocagem.

A incorporação do cálculo do lote econômico de produção à rotina do cálculo de custos das emprêsas contribuirá para 
tornar mais generalizada a prática de orçar e variar os preços em função das quantidades pedidas por períodos. Será êsse, também, um meio eficiente de evitar a não-absorção das despesas gerais. Finalmente, a melhor compreensão da fixação das quantidades mais adequadas aos fornecimentos industriais ajudará compradores e fornecedores a operar de forma mais eficiente, econômica e harmoniosa. 


\section{ANEXO I}

A fim de oferecer ao leitor uma aplicação numérica de determinação da freqüência de ciclos anuais de produção, recorremos ao exemplo abaixo. $\left(^{5}\right)$

Determinar a duração total do ciclo de produção dos produtos especificados na seguinte tabela:

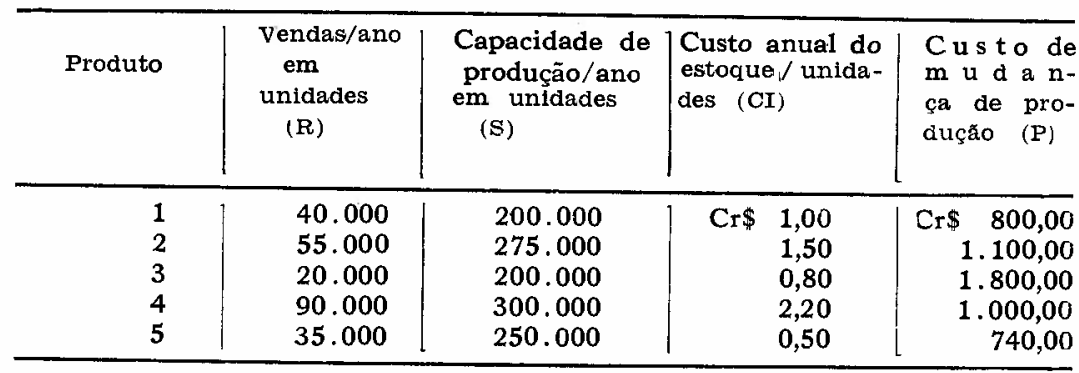

SOLUÇÃO:

\begin{tabular}{|c|c|c|c|c|c|}
\hline Prculuto & $\begin{array}{l}\mathbf{R}_{\mathrm{i}} \\
\mathbf{S}_{\mathrm{i}} \\
(1)\end{array}$ & $1-\frac{R_{i}}{S_{i}}$ & $\begin{array}{c}R_{i} C_{i} I_{i} \\
(3)\end{array}$ & $\begin{array}{l}\mathbf{R}_{i} C_{i} I_{i}\left\{1-\frac{R_{i}}{S_{i}}\right\} \\
(4)=(2) \times(3)\end{array}$ & $\begin{array}{l}P_{i} \\
(5)\end{array}$ \\
\hline $\begin{array}{l}1 \\
2 \\
3 \\
4 \\
5\end{array}$ & $\begin{array}{l}0,20 \\
0,20 \\
0,10 \\
0,30 \\
0,14\end{array}$ & $\begin{array}{l}0,80 \\
0,80 \\
0,90 \\
0,70 \\
0,86\end{array}$ & $\begin{array}{r}40.000 \\
82.500 \\
16.000 \\
198.000 \\
17.500\end{array}$ & $\begin{array}{r}32.000 \\
66.000 \\
14.400 \\
136.600 \\
15.100\end{array}$ & $\begin{array}{r}800 \\
1.100 \\
1.800 \\
1.000 \\
740\end{array}$ \\
\hline & & & & 266.100 & 5.440 \\
\hline
\end{tabular}

$=u \quad \sqrt{\frac{\Sigma \text { Col. (4) }}{2 \Sigma \text { Col. (5) }}}=\sqrt{\frac{266.100}{2 \times 5.440}}=$

$=\sqrt{24,5} \simeq 5$ ciclos $/$ ano

5) John F. Magee, op. cit. págs. 58 e 59. 
De acôrdo com a capacidade do equipamento, o total vendido corresponde a uma utilização de 235 dias (considerando o ano útil de 250 dias), em virtude do seguinte cálculo:

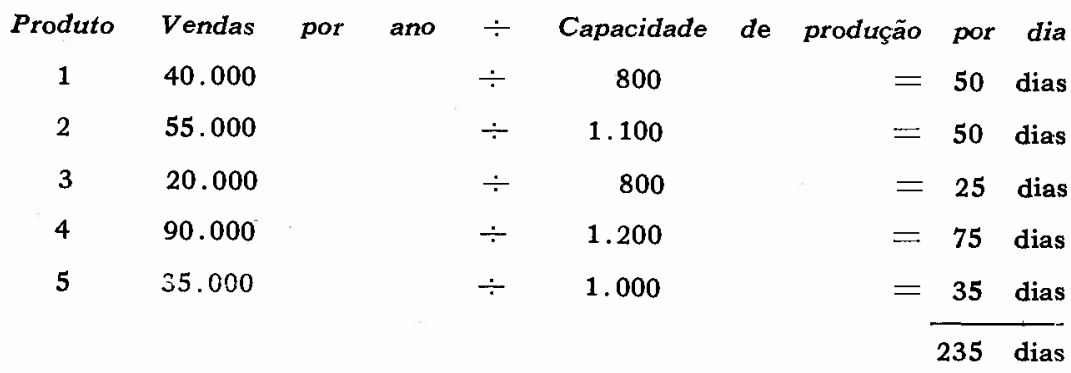

Assim, o custo mínimo de operação será obtido quando cada ciclo tiver a duração de $\frac{235}{5}=47$ dias, produzindo-se em cada ciclo aproximadamente $20 \%$ das necessidades totais de venda.

\section{BIBLIOGRAFIA}

H. G. Thuessen, Engineering Economy, Prentice-Hall Inc., New York, 1950.

E. H. Bowman e R. B. Fetter, Analysis for Production Management, Richard D. Irwin, Inc., Homewcod, III., 1957.

G. B. Carson, Production Handbook, Ronald Press Co., New York, 1958, cap. 2. J. F. Magee, Production Planning and Inventory Control, McGraw-Hill Book Co., Inc., New York, 1958.

F. Hanssmann, Operations Research in Production and Inventory Control, John Wiley and Sons, New York, 1962. 